\title{
Propylthiouracil-induced hypothyroidism is associated with increased tolerance of the isolated rat heart to ischaemia-reperfusion
}

\author{
C Pantos, V Malliopoulou, I Mourouzis, K Sfakianoudis, S Tzeis, \\ P Doumba, C Xinaris, A D Cokkinos, H Carageorgiou, \\ D D Varonos and D V Cokkinos ${ }^{1}$
}

Department of Pharmacology, University of Athens, 75 Mikras Asias Avenue, 11527 Goudi, Athens, Greece

${ }^{1}$ First Cardiology Department, Onassis Cardiac Surgery Center, 356 Sygrou Avenue, 17674 Kallithea, Athens, Greece

(Requests for offprints should be addressed to C Pantos; Email: cpantos@cc.uoa.gr)

\begin{abstract}
The present study investigated the response of the hypothyroid heart to ischaemia-reperfusion. Hypothyroidism was induced in Wistar rats by oral administration of propylthiouracil (0.05\%) for 3 weeks (HYPO rats), while normal animals (NORM) served as controls. Isolated hearts from NORM and HYPO animals were perfused in Langendorff mode and subjected to zero-flow global ischaemia followed by reperfusion (I/R). Post-ischaemic recovery of left ventricular developed pressure was expressed as \% of the initial value (LVDP\%). Basal expression of protein kinase $\mathrm{C} \varepsilon(\mathrm{PKC} \varepsilon)$ and $\mathrm{PKC} \delta$ and phosphorylation of p46 and p54 c-jun $\mathrm{NH}_{2}$-terminal kinases (JNKs) in response to I/R were assessed by Western blotting. LVDP\% was found to be significantly
\end{abstract}

higher in HYPO hearts than in NORM. At baseline, PKCE expression was $1 \cdot 4$-fold more in HYPO than in NORM hearts, $P<0 \cdot 05$, while PKC $\delta$ was not changed. Furthermore, basal phospho-p54 and -p46 JNK levels were $2 \cdot 2-$ and $2 \cdot 6$-fold more in HYPO than in NORM hearts, $P<0 \cdot 05$. In response to $\mathrm{I} / \mathrm{R}$, in NORM hearts, phospho-p54 and -p46 JNK levels were $5 \cdot 5$ - and 6.0-fold more as compared with the baseline values, $P<0 \cdot 05$, while they were not significantly altered in HYPO hearts. HYPO hearts seem to display a phenotype of cardioprotection against ischaemia-reperfusion and this is associated with basal PKCE overexpression and attenuated JNK activation after I/R.

Journal of Endocrinology (2003) 178, 427-435

\section{Introduction}

Hypothyroidism is a common clinical condition with various consequences on the cardiovascular system and has been associated with increased cardiovascular morbidity (Hak et al. 2000, Vanderpump et al. 2002). Furthermore, circulating thyroid hormone levels have been demonstrated to decline $\left(3,5,3^{\prime}\right.$-triiodothyronine $\left(\mathrm{T}_{3}\right)$ more and to a lesser extent L-thyroxine $\left.\left(\mathrm{T}_{4}\right)\right)$ in various conditions such as acute myocardial infarction (Franklyn et al. 1984), congestive heart failure (Hamilton et al. 1998) or diabetes (Yue et al. 1998). Abnormal thyroid function also occurs after cardiac surgery requiring cardiopulmonary bypass (Bartkowski et al. 2002) or chronic administration of amiodarone (Klein \& Ojamaa 2001).

It has been long realized that the heart is one of the most thyroid hormone-responsive tissues (Klein \& Ojamaa 2001). In fact, thyroid hormone is shown to regulate the transcription of various myocyte-specific genes that encode important structural and regulatory proteins including myosin heavy chain isoforms $\alpha$ and $\beta$, sarcoplasmic reticulum calcium activated ATPase $\left(\mathrm{SR} \mathrm{Ca}^{2+}\right.$ ATPase), phospholamban, the $\beta$-adrenergic receptor, adenylyl cyclase isoforms and various membrane ion channels (Klein \& Ojamaa 2001). Furthermore, recent research has revealed that thyroid hormone can interfere with the regulation of important intracellular signalling transduction pathways (Fryer et al. 1998, Pantos et al. 2001, 2002a, 2003a) that are thought to be involved in protection against ischaemia-reperfusion (I/R) (Speechly-Dick et al. 1994, Kawamura et al. 1998, Zhao et al. 1998, Pantos et al. 2000, 2001, Fryer et al. 2001). In fact, chronic administration of $\mathrm{T}_{4}$ results in changes in cardioprotective molecules such as protein kinase $\mathrm{C}$ (PKC) and mitogenactivated protein kinases (Fryer et al. 1998, Pantos et al. 2001, 2002a, 2003a) and this was shown to be associated with increased post-ischaemic recovery of function (Buser et al. 1990, Pantos et al. 2002a, 2003a,c).

On the basis of this evidence, thyroid hormone seems to be an important regulator of cardiac performance as well as 
of the response of the heart to ischaemic stresses and consequently one could anticipate that low thyroid hormone states might lead to impaired myocardial performance and increased susceptibility of the heart to ischaemia. This hypothesis, although of clinical relevance, has not been previously adequately explored. Therefore, the present study investigated the response of the isolated rat heart to $\mathrm{I} / \mathrm{R}$ in an experimental model of propylthiouracil-induced hypothyroidism.

\section{Materials and Methods}

\section{Animals}

Forty-two Wistar male rats, 270-320 g were used for this study. The rats were handled in accordance with the Guide for the Care and Use of Laboratory Animals published by the US National Institutes of Health (NIH Publication No 85-23, revised 1985). Anaesthesia was achieved with i.p. injection of ketamine hydrochloric acid $(150 \mathrm{mg} / \mathrm{kg})$.

\section{Experimental hypothyroidism}

Hypothyroidism was induced in rats by administration of 6-n-propyl-2-thiouracil in drinking water to a final concentration of $0.05 \%$ for 3 weeks (Cernohorsky et al. 1998, Shenoy et al. 2001). These animals were designated as HYPO. Untreated rats were used as controls and were designated as NORM.

\section{Isolated heart preparation}

A non-ejecting isolated rat heart preparation was perfused at constant coronary flow according to the Langendorff technique, as previously described (Pantos et al. 2000, $2002 b, 2003 b)$. In this model, coronary flow per gram of cardiac tissue was similar in all the experimental groups. Rats were anaesthetized with i.p. injection of ketamine hydrochloric acid and heparin (1000 IU/kg body weight) was given i.v. before thoracotomy. The hearts were perfused with oxygenated $\left(95 \% \mathrm{O}_{2} / 5 \% \mathrm{CO}_{2}\right)$ KrebsHenseleit buffer at a constant temperature of $37^{\circ} \mathrm{C}$ and were paced at $320 \mathrm{bpm}$ with a Harvard pacemaker. The pacemaker was turned off during the period of ischaemia. An intraventricular balloon allowed measurement of contractility under isovolumic conditions. Left ventricular balloon volume was adjusted to produce an average initial left ventricular end-diastolic pressure (LVEDP) of 6 $\mathrm{mmHg}$ in all groups and was held constant thereafter throughout the experiment. Pressure signal was transferred to a personal computer using data analysis software (IOX; Emka Technologies, Paris, France). Cardiac function was assessed by left ventricular peak systolic pressure and the left ventricular developed pressure (LVDP), defined as the difference between left ventricular peak systolic pressure and LVEDP. LVDP and its positive and negative first derivative $(+d \mathrm{p} / \mathrm{dt},-\mathrm{dp} / \mathrm{dt})$ were measured at the end of the stabilization and reperfusion period respectively. Postischaemic cardiac function was assessed by the recovery of LVDP which was expressed as \% of the initial value (LVDP\%) and by LVEDP at $45 \mathrm{~min}$ of reperfusion. Ischaemic contracture was assessed by measurement of the observed increase in left ventricular pressure at various time points during ischaemia.

\section{Total protein preparation}

Isolation of total protein content and Western blotting have been performed as previously described (Pantos et al. 2001, 2002a, 2003a). Approximately $0 \cdot 2 \mathrm{~g}$ frozen tissue was homogenized in ice-cold Tris-sucrose buffer $(0 \cdot 35 \mathrm{M}$ sucrose, $10 \mathrm{mM}$ Tris- $\mathrm{HCl} \mathrm{pH}$ 7.5, $1 \mathrm{mM}$ EDTA, $0.5 \mathrm{mM}$ dithiothreitol, $0.1 \mathrm{mM}$ phenylmethanesulfonyl fluoride) with a Polytron homogenizer and the resulting homogenate was centrifuged at $15000 \boldsymbol{g}$ for $20 \mathrm{~min}$ at $4{ }^{\circ} \mathrm{C}$. The supernatant, representing the total cell extract, was used for immunoblotting. Protein concentrations were determined by the bicinchoninic acid method using BSA (Walker 1994).

\section{SDS-PAGE and immunoblotting}

After boiling for $5 \mathrm{~min}$ in Laemmli sample buffer, protein aliquots $(40 \mu \mathrm{g})$ were loaded onto $10 \%(\mathrm{w} / \mathrm{v})$ acrylamide gels and subjected to SDS-PAGE. After Western blotting, filters were probed with specific antibodies against either PKC $\varepsilon$ or PKC $\delta$ (Transduction Laboratories, Lexington, $\mathrm{KY}$, USA, dilution 1:1000), or total $\mathrm{c}$-jun $\mathrm{NH}_{2}$-terminal kinases (JNKs) or dual phospho-JNKs (New England Biolabs, Hitchin, Herts, UK, dilution 1:1000), or actin (Sigma, 1:1000) overnight at $4{ }^{\circ} \mathrm{C}$ and immunoreactivity was detected by enhanced chemiluminescence. Immunoblots were quantified using the AlphaScan Imaging Densitometer (Alpha Innotech Corporation, San Leaudro, CA, USA). For comparisons between groups, five samples from each group were loaded on the same gel. Optical densities of PKC $\varepsilon, \operatorname{PKC} \delta$, dual phospho-JNKs and total JNK immunoreactivity were expressed as a ratio of the actin optical density to correct for slight variations in total protein loading.

\section{Experimental protocol}

Hearts from NORM and HYPO rats were subjected only to $20 \mathrm{~min}$ of stabilization, NORM-Base, $n=5$ and HYPO-Base, $n=5$.

Hearts from NORM and HYPO rats were subjected to $20 \mathrm{~min}$ of stabilization, $20 \mathrm{~min}$ of zero-flow global ischaemia and $45 \mathrm{~min}$ of reperfusion, NORM-20I/R, $n=8$, and HYPO-20I/R, $n=8$. Since ischaemic contracture did not reach a plateau within $20 \mathrm{~min}$ of ischaemia, 
Table 1 Initial body weight (BW1 in g), body weight after 3 weeks of treatment (BW2 in g), left ventricular weight (LVW in $\mathrm{mg}$ ), the ratio of left ventricular weight to body weight (LVW/BW in $\mathrm{mg} / \mathrm{g}$ ), $\mathrm{T}_{3}$ and $\mathrm{T}_{4}$ levels in plasma (nmol/l) for NORM and HYPO rats. The values are means \pm S.E.M.

\begin{tabular}{|c|c|c|}
\hline & \multicolumn{2}{|l|}{ Group } \\
\hline & NORM & HYPO \\
\hline BW1 & $305 \pm 7 \cdot 9$ & $307 \pm 2 \cdot 6$ \\
\hline BW2 & $338 \pm 9 \cdot 9$ & $268 \pm 9 \cdot 1^{*}$ \\
\hline LVW & $831 \pm 27 \cdot 7$ & $675 \pm 20 \cdot 2^{*}$ \\
\hline LVW/BW2 & $2 \cdot 4 \pm 0 \cdot 05$ & $2 \cdot 5 \pm 0.09$ \\
\hline $\mathrm{T}_{3}$ & $0 \cdot 87 \pm 0 \cdot 04$ & $0 \cdot 23 \pm 0.05^{*}$ \\
\hline $\mathrm{T}_{4}$ & $52 \cdot 50 \pm 2 \cdot 63$ & $19 \cdot 97 \pm 0 \cdot 38^{*}$ \\
\hline
\end{tabular}

${ }^{*} P<0 \cdot 05$ vs NORM.

hearts from NORM and HYPO animals were also subjected to $20 \mathrm{~min}$ of stabilization, $30 \mathrm{~min}$ of zero-flow global ischaemia and $45 \mathrm{~min}$ of reperfusion, NORM-30I/R, $n=8$, and HYPO-30I/R, $n=8$.

\section{Measurement of thyroid hormones}

Plasma $T_{4}$ and $T_{3}$ quantitative measurements were performed by using ${ }^{125}$ I RIA kits obtained from DiaSorin,

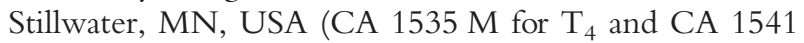
for $\left.\mathrm{T}_{3}\right) \cdot \mathrm{T}_{4}$ and $\mathrm{T}_{3}$ levels were expressed as $\mathrm{nmol} / \mathrm{l}$ of plasma.

\section{Statistics}

Values are presented as means \pm S.E.M. The unpaired $t$-test and Mann-Whitney test were used for differences between groups. A two-tailed test with a $P$ value less than 0.05 was considered significant.

\section{Results}

Thyroid hormones and alterations in animal body weight and heart weight

Propylthiouracil administration resulted in a significant decrease of thyroid hormone levels in plasma (Table 1). Animal body weight and left ventricular weight were significantly decreased in HYPO compared with NORM rats (Table 1).

\section{Basal and post-ischaemic cardiac function}

Basal cardiac contractility was found to be significantly reduced in HYPO as compared with NORM rats (Table 2). Post-ischaemic recovery of function was found to be significantly improved in hearts from HYPO animals as compared with NORM hearts after either 20 or $30 \mathrm{~min}$ of ischaemia (Fig. 1; Table 2).

\section{Ischaemic contracture profile}

Profiles of ischaemic contracture are shown in Fig. 2. Within 20 min of ischaemia, neither NORM nor HYPO hearts reached a plateau, although HYPO hearts displayed a significant attenuation of the rise of diastolic pressure. Within $30 \mathrm{~min}$ of ischaemia, ischaemic contracture reached a maximum at $25 \cdot 3 \pm 1 \cdot 4 \mathrm{~min}$ in NORM hearts, while in HYPO hearts it did not reach a peak.

\section{$P K C \varepsilon$ and $P K C \delta$ protein expression at baseline}

PKC $\delta$ protein expression at baseline was not different between NORM and HYPO hearts, $P>0 \cdot 05$. However, PKC $\varepsilon$ protein expression at baseline was 1.4-fold more in HYPO-Base than in NORM-Base hearts, $P<0.05$ (Fig. 3).

Table 2 Left ventricular developed pressure (LVDP, $\mathrm{mmHg}),+\mathrm{dp} / \mathrm{dt}(\mathrm{mmHg} / \mathrm{s})$ and $-\mathrm{dp} / \mathrm{dt}(\mathrm{mmHg} / \mathrm{s})$ at the end of the stabilization period for NORM and HYPO hearts as well as LVDP\%, LVDP and left ventricular end-diastolic pressure (LVEDP, $\mathrm{mmHg}$ ) at $45 \mathrm{~min}$ of reperfusion (R) for NORM and HYPO hearts subjected to 20 or $30 \mathrm{~min}$ of ischaemia. $\mathrm{l} / \mathrm{R}=$ ischaemia/reperfusion. The values are means \pm S.E.M.

\begin{tabular}{|c|c|c|c|c|}
\hline & \multicolumn{4}{|l|}{ Group } \\
\hline & $\begin{array}{l}\text { NORM-20l/R } \\
(n=8)\end{array}$ & $\begin{array}{l}\text { HYPO-20I/R } \\
(n=8)\end{array}$ & $\begin{array}{l}\text { NORM-30l/R } \\
(n=8)\end{array}$ & $\begin{array}{l}\text { HYPO-30l/R } \\
(n=8)\end{array}$ \\
\hline LVDP (baseline) & $129 \cdot 3 \pm 4 \cdot 5$ & $103 \cdot 8 \pm 2 \cdot 3^{*}$ & $133 \cdot 9 \pm 4 \cdot 5$ & $109 \cdot 0 \pm 3 \cdot 6^{\star *}$ \\
\hline$+\mathrm{dp} / \mathrm{dt}$ (baseline) & $5150 \pm 280$ & $3417 \pm 135^{*}$ & $4476 \pm 227$ & $3200 \pm 259 * *$ \\
\hline - dp/dt (baseline) & $2615 \pm 112$ & $1851 \pm 47^{*}$ & $2461 \pm 149$ & $1731 \pm 85^{* *}$ \\
\hline LVDP at $45 \min R$ & $80 \cdot 1 \pm 6 \cdot 5$ & $96 \cdot 3 \pm 3 \cdot 6^{*}$ & $15 \cdot 6 \pm 3 \cdot 1$ & $65 \cdot 9 \pm 10 \cdot 8^{* *}$ \\
\hline LVEDP at $45 \mathrm{~min} \mathrm{R}$ & $52 \cdot 8 \pm 5 \cdot 6$ & $12 \cdot 3 \pm 3 \cdot 4^{*}$ & $105 \cdot 8 \pm 3 \cdot 6$ & $36 \cdot 0 \pm 7 \cdot 7^{* *}$ \\
\hline LVDP\% & $60 \cdot 6 \pm 5 \cdot 1$ & $93 \cdot 1 \pm 4 \cdot 1^{*}$ & $11 \cdot 5 \pm 2 \cdot 1$ & $61 \cdot 3 \pm 11 \cdot 0^{* *}$ \\
\hline
\end{tabular}



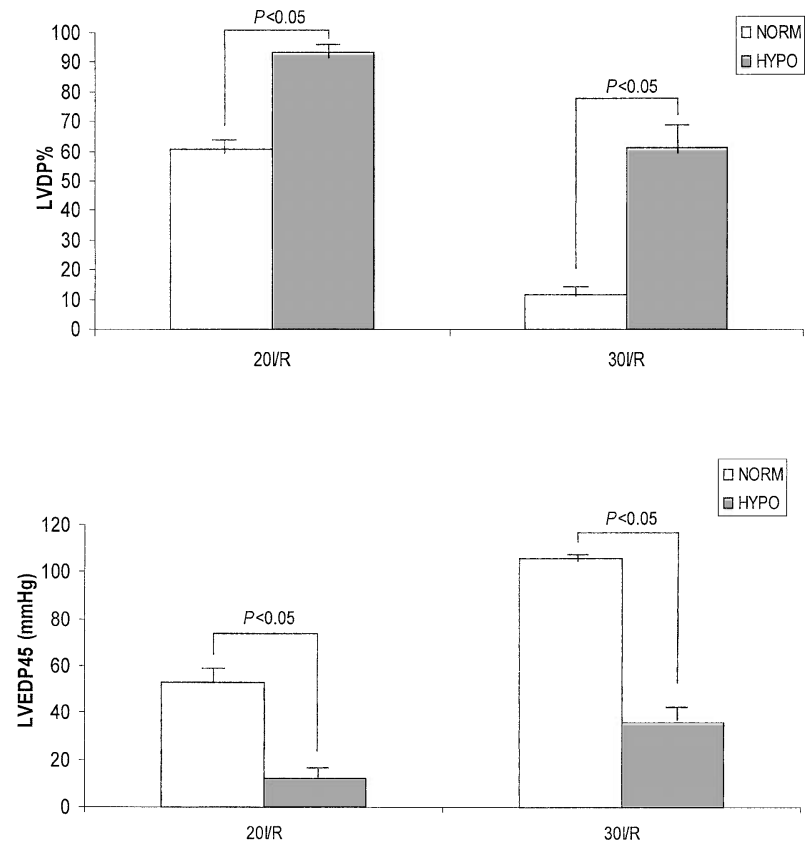

Figure 1 Post-ischaemic recovery of function, LVDP\%, (upper panel) and left ventricular end-diastolic pressure at $45 \mathrm{~min}$ of reperfusion, LVEDP45, (bottom panel) in normal hearts (NORM) and hearts from hypothyroid rats (HYPO) subjected to 20 or $30 \mathrm{~min}$ of ischaemia. $($ Bar $=$ S.E.M. $)$

\section{Phosphorylation of $p 54$ and $p 46 \mathrm{JNKs}$ after $I / R$}

The levels of phospho-p54 and -p46 JNKs were found to be 2.2- and 2.6-fold more in HYPO-Base than in NORM-Base hearts respectively, $P<0 \cdot 05$. After I/R, the levels of phospho-p54 and -p46 JNKs were increased 5.5and $6 \cdot 0$-fold respectively in NORM-20I/R as compared with NORM-Base hearts, $P<0 \cdot 05$. On the contrary, there was not a significant increase in the levels of the phospho-JNKs in HYPO-20I/R as compared with HYPO-Base. The levels of phospho-p54 and -p46 JNKs were $1 \cdot 8$ - and $2 \cdot 2$-fold less in HYPO-20I/R hearts as compared with NORM-20I/R hearts respectively, $P<0.05$ (Fig. 4).

\section{Discussion}

Recent research has pointed out the important role of thyroid hormone in the response of the cardiac cell to ischaemic stress. In fact, excess of thyroid hormone can result in increased tolerance of the heart against I/R (Buser et al. 1990, Walker et al. 1995, Liu et al. 1998, Pantos et al. 2000) and PKC $\delta$ and p38 mitogen-activated protein kinase are suggested to be important elements of this response (Pantos et al. 2001, 2002a,b). The present study has explored the possibility that decreased thyroid hormone levels could potentially have detrimental effects on the tolerance of the heart to ischaemia.

An experimental model of hypothyroidism was induced by administration of propylthiouracil for a period of 3 weeks. This treatment resulted in short-term hypothyroidism with significant but not marked decrease of $T_{4}$ and $\mathrm{T}_{3}$ levels in plasma. Animal body weight and heart weight were found to be reduced in HYPO rats whereas baseline myocardial functional parameters were impaired in HYPO hearts as compared with NORM. These findings are consistent with previous reports (Cernohorsky et al. 1998, Shenoy et al. 2001, Ohga et al. 2002). In fact, cardiac dysfunction is a common finding in the hypothyroidism and this has been attributed to various changes that occur in the myocardium (Ohga et al. 2002). Such changes include increased expression of V3 isomyosin, reduced expression of SR $\mathrm{Ca}^{2+}$-ATPase and ryanodine receptor and enhanced expression of phospholamban (Arai et al. 1991, Kiss et al. 1994, Ohga et al. 2002).

In response to I/R, HYPO hearts displayed an increased post-ischaemic recovery of function as compared with NORM while ischaemic contracture occurred later in those hearts. Several studies have concluded similar results. Abe et al. (1992), using an isolated working heart model, demonstrated increased recovery of the pressurerate product in HYPO hearts as compared with NORM. Furthermore, Eynan et al. (2002) showed an improved post-ischaemic recovery of function and delayed ischaemic contracture in isolated HYPO rat hearts subjected to zero-flow global ischaemia. Along the same line, Zhang et al. (2002) have recently demonstrated that hypothyroidism can be protective against I/R arrhythmias.

The mechanisms that underlie hypothyroidism-induced cardioprotection are not fully understood and changes in metabolism or energy utilization have been suggested to be implicated in this effect. In fact, it is thought that HYPO hearts have a higher efficiency and consume less oxygen in doing mechanical work due to the predominance of V3 myosin isoform. As a consequence, in HYPO hearts, ATP levels are found to decline more slowly during ischaemia and are higher at reperfusion (Abe et al. 1992). Furthermore, other studies show that pre-ischaemic myocardial glycogen levels are higher in those hearts whereas glycolysis during ischaemia is slowed (Eynan et al. 2002). However, it has been recently reported that hearts displaying opposite metabolic characteristics such as hyperthyroid hearts are also found to be more tolerant to ischaemia (Buser et al. 1990, Van der Vusse et al. 1998, Pantos et al. 2000, 2001, 2002a,b) indicating that the increased resistance of the HYPO heart to ischaemia cannot be merely explained on the basis of the metabolic changes that are observed in those hearts.

It is now realized that intracellular molecules such as PKC and/or mitogen-activated protein kinases could play an important role in the adaptive response of the heart to ischaemia. The role of PKC and its isotypes in 

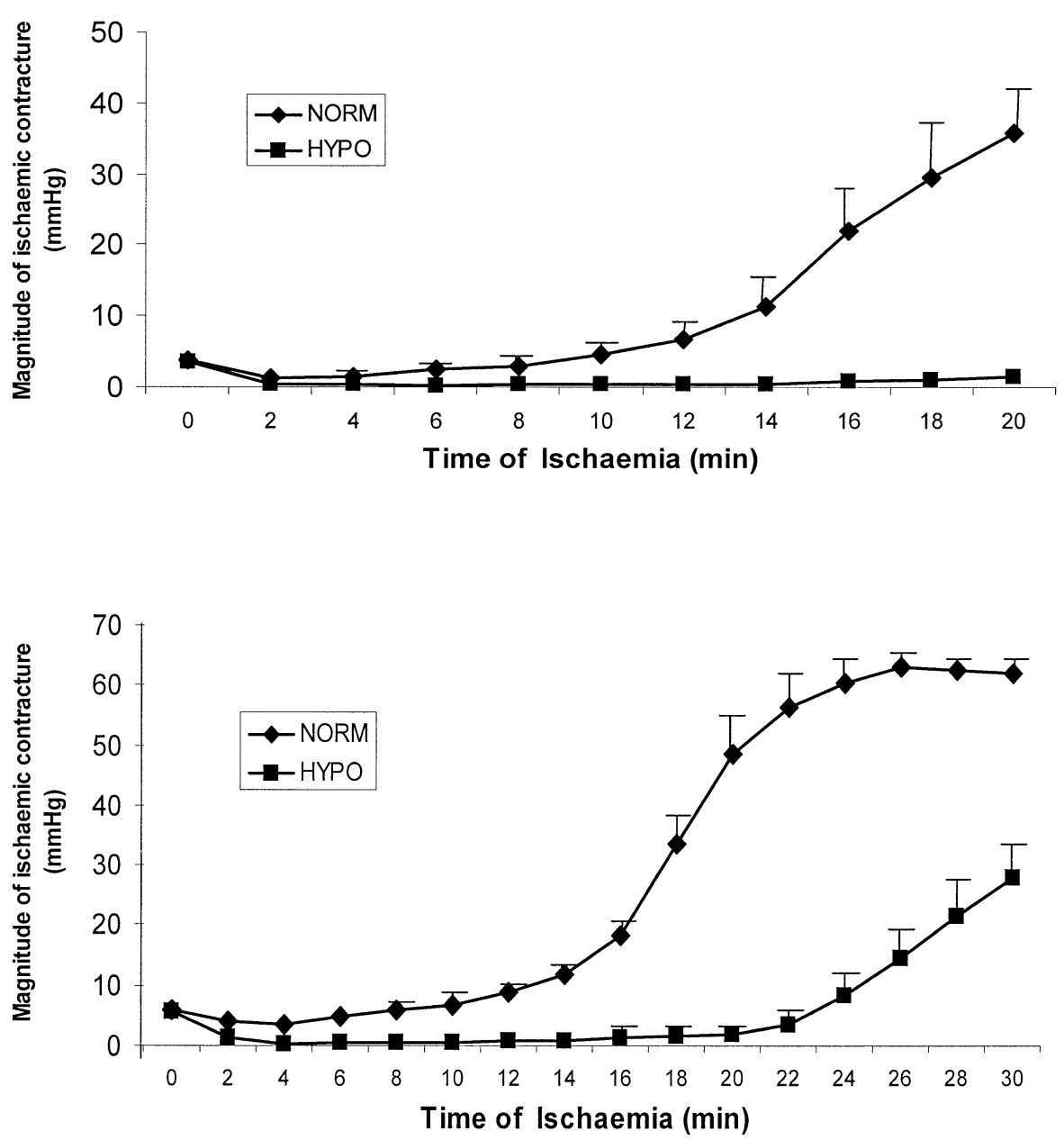

Figure 2 Ischaemic contracture profiles of normal hearts (NORM) and hearts from hypothyroid rats (HYPO) subjected to $20 \mathrm{~min}$ (upper panel) or $30 \mathrm{~min}$ (bottom panel) of ischaemia. (Bar=S.E.M.)

cardioprotection has been demonstrated by various studies (Speechly-Dick et al. 1994, Kawamura et al. 1998). In fact, PKC $\varepsilon$ has been shown to be mainly involved in cardioprotective means such as ischaemic preconditioning (Fryer et al. 2002) while PKC $\delta$ has been implicated in pharmacological preconditioning (Fryer et al. 2001). Interestingly, chronic $\mathrm{T}_{4}$ administration is shown to upregulate $\mathrm{PKC} \delta$ (Fryer et al. 1998, Pantos et al. 2002a) and induce pharmacological preconditioning (Pantos et al. 2002a), while cells overexpressing PKC $\delta$ (Zhao et al. 1998) or hearts from mice overexpressing PKC $\varepsilon$ are found to be less susceptible to ischaemia (Cross et al. 2002). In the present study, PKCE expression was found to be increased in HYPO hearts while PKC $\delta$ expression remained unchanged. On the basis of these data, it could be suggested that PKCE overexpression is likely to be linked to the increased resistance of those hearts to ischaemia. In support of this notion is the fact that HYPO hearts closely resemble hearts from mice overexpressing $\mathrm{PKC} \varepsilon$ as regards the response to ischaemia as well as ATP utilization during $\mathrm{I} / \mathrm{R}$; in a transgenic model overexpressing PKC $\varepsilon$ in the myocardium, ATP levels were found to decline more slowly during ischaemia and to be higher at reperfusion while post-ischaemic recovery was significantly improved in those hearts (Cross et al. 2002). Furthermore, PKCE overexpression is also shown to occur in hearts from diabetic rats that are found to be tolerant to ischaemia and abnormal thyroid function frequently coexist (Liu et al. 1999).

Recent research has emphasized the important role of JNK-dependent pathways in determining the response of the cell against various stresses (Bogoyevitch et al. 1996). JNKs are found to be activated in stressful conditions and this has been associated with cell death (Chen et al. 1996) while inhibition of JNK activation is shown to prevent cell injury induced by a variety of stresses, including heat shock, ethanol, UV irradiation, oxidative stress and other (Gabai et al. 1998). This has been clearly demonstrated in 
PKCס

Arbitrary Unit
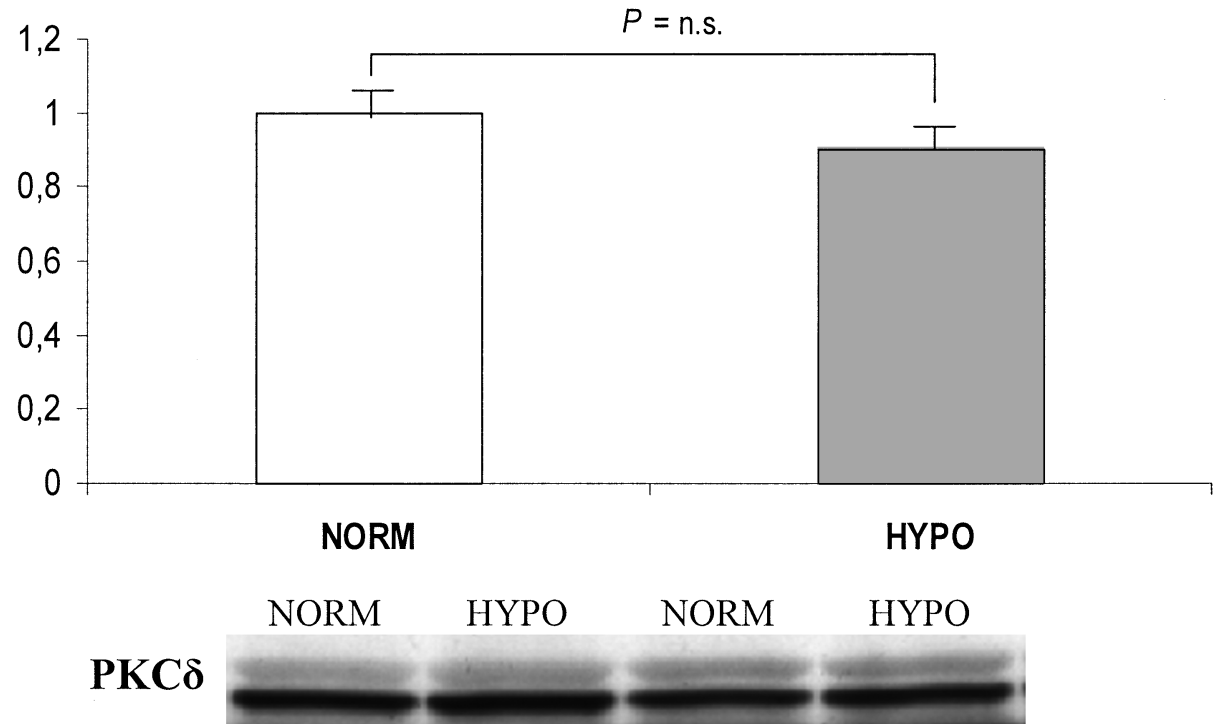

PKC $\varepsilon$

Arbitrary Unit
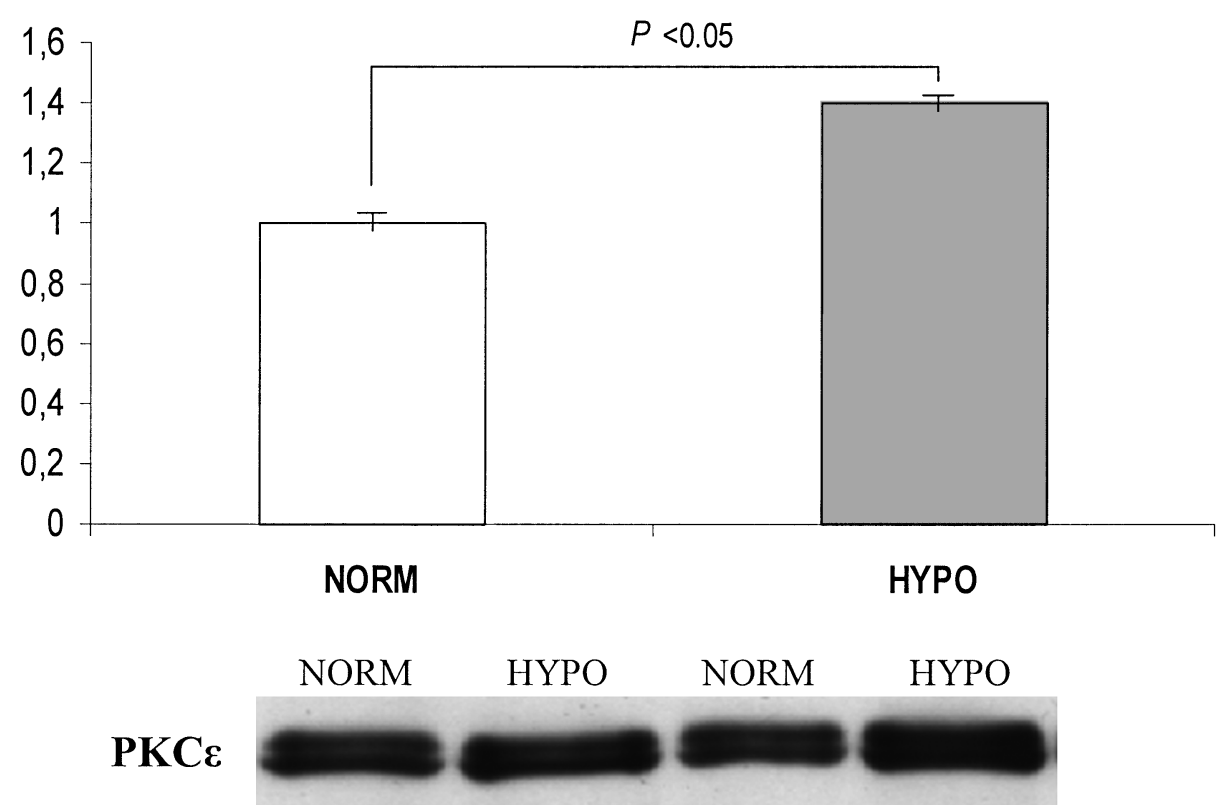

Figure 3 Densitometric assessment of PKC $\delta$ (upper panels) and PKC $\varepsilon$ (bottom panels) expression in normal hearts (NORM, $n=5$ ) and hearts from hypothyroid rats (HYPO, $n=5)$. (Columns are means of optical ratios, bar=S.E.M.) 

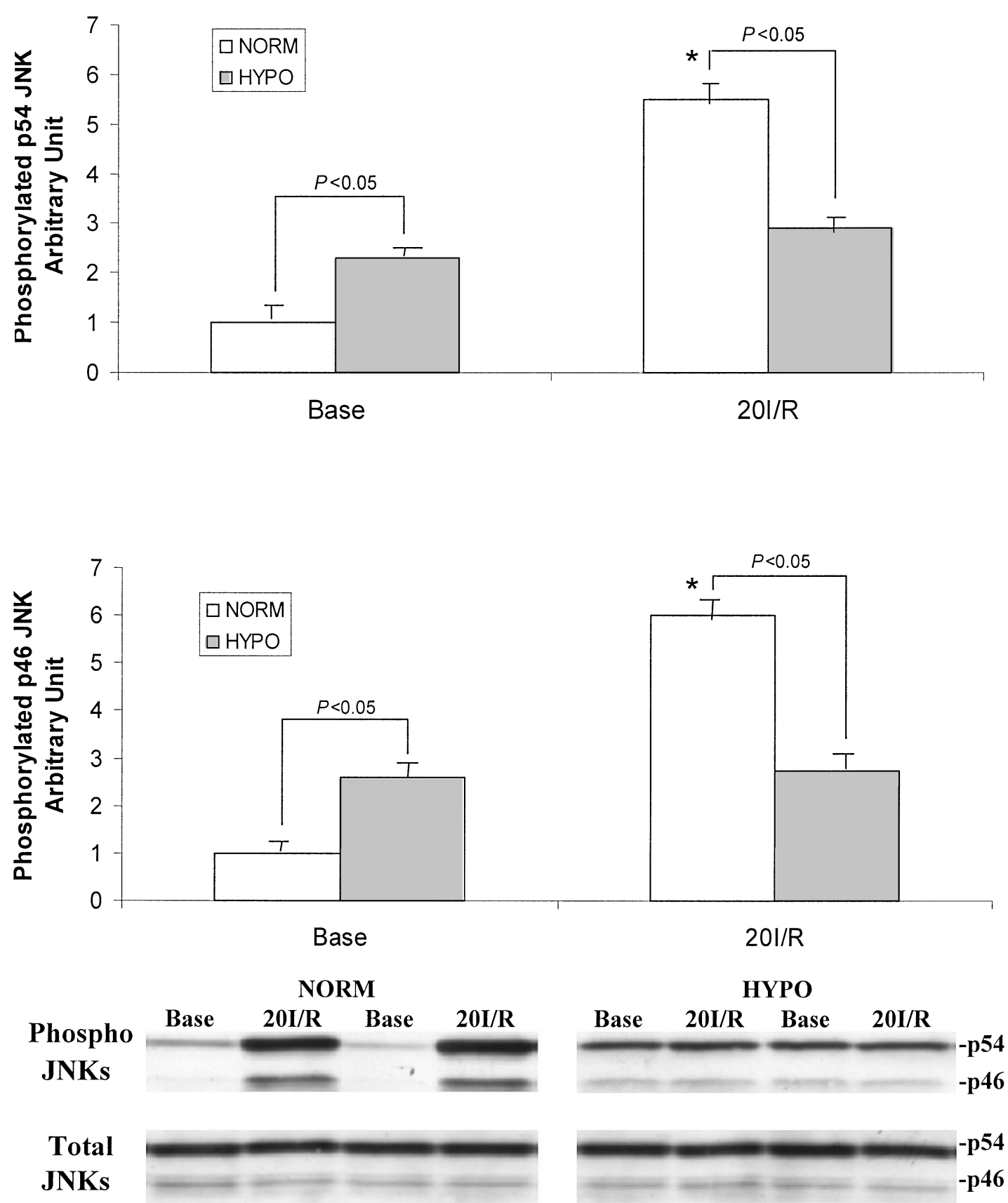

Figure 4 (Upper panels) Densitometric assessment of phosphorylated JNKs in normal hearts (NORM) and hearts from hypothyroid rats (HYPO) at baseline (Base, $n=5$ for each group) and after $20 \mathrm{~min}$ of ischaemia and reperfusion (20l/R, $n=5$ for each group). (Columns are means of optical ratios, bar $=$ S.E.M.) ${ }^{*} P<0.05$ vs NORM-Base. (Lower panel) Western blots showing phosphorylated and total JNKs in NORM and HYPO hearts at baseline (Base, $n=5$ for each group) and after 20 min of ischaemia and reperfusion (20I/R, $n=5$ for each group).

cell-based models by interruption of the JNK signalling pathway, either immediately upstream of JNK by expression of dominant negative mutants of the JNK activator SEK1 (Verheij et al. 1996), or immediately downstream of JNK, by an expression of a dominant negative mutant of
JNK substrate, c-jun (Gabai et al. 1997). In the present study, JNKs were found to be significantly activated in NORM hearts in response to the I/R sequence. In fact, the levels of phospho-p46 and -p54 JNK after I/R were found to be 6 - and 5 -fold more than the baseline values. 
On the contrary, in HYPO hearts, the levels of phosphop46 and -p54 JNK were not increased after I/R. On the basis of these data, it seems likely that inhibition of JNK activation during I/R might be an important element of HYPO-induced cardioprotection. Several lines of evidence support this notion. Recent studies demonstrate that in established paradigms of cardioprotection such as ischaemic preconditioning and heat stress pretreatment, JNK activation is also found to be attenuated during the subsequent I/R (Sato et al. 2000, Pantos et al. 2003b,c). The fact that both hypothyroidism and preconditioning reduce the JNK activation in response to $\mathrm{I} / \mathrm{R}$ might indicate that JNK is an essential component of the protection conferred by these two interventions. It is also of note that carvedilol administration at reperfusion is shown to increase tolerance of the heart to ischaemia while JNK activation is attenuated (Yue et al. 1998).

It appears from this study and from previous studies that thyroid hormone can play an important role in the response of the heart to ischaemia. Long-standing alterations in thyroid hormone can induce adaptive changes in the myocardium with important physiological consequences as regards the cardioprotection. Different underlying mechanisms seem to exist between the hypothyroid- and hyperthyroid-induced cardioprotection and this issue needs to be further investigated.

In conclusion, propylthiouracil-induced hypothyroidism increases post-ischaemic recovery of function and this was associated with basal PKCe overexpression and attenuated JNK activation in response to I/R.

\section{Acknowledgement}

This research has been supported by the Bodosakis Institution research funds

\section{References}

Abe M, Obata H \& Tanaka H 1992 Functional and metabolic responses to ischaemia in the isolated perfused hypothyroid rat heart. Japanese Circulation Journal 56 671-680.

Arai M, Otsu K, MacLennan DH, Alpert NR \& Periasamy M 1991 Effect of thyroid hormone on the expression of mRNA encoding sarcoplasmic reticulum proteins. Circulation Research 69 266-276.

Bartkowski R, Wojtalik M, Korman E, Sharma G, Henschke J \& Mrowcznski W 2002 Thyroid hormone levels in infants during and after cardiopulmonary bypass with ultrafiltration. European Journal of Cardio-thoracic Surgery 22 879-884.

Bogoyevitch M, Gillespie-Brown J, Ketterman A, Fuller S, Ben-Levy R, Ashworth A, Marshall CJ \& Sugden PH 1996 Stimulation of the stress-activated mitogen-activated protein kinase subfamilies in perfused heart: p38/RK mitogen-activated protein kinases and c-jun N-terminal kinases are activated by ischemia/reperfusion. Circulation Research 79 162-173.

Buser PT, Wikman Coffelt J, Wu ST, Derugin N, Papmley WW \& Higgins CB 1990 Postischemic recovery of mechanical performance and energy metabolism in the presence of left ventricular hypertrophy. A ${ }^{31} \mathrm{P}-\mathrm{NMR}$ study. Circulation Research 66 735-746.

Cernohorsky J, Kolar F, Pelouch V, Korecky B \& Vetter R 1998 Thyroid control of sarcolemmal $\mathrm{Na}^{+} / \mathrm{Ca}^{2+}$ exchanger and SR $\mathrm{Ca}^{2+}$-ATPase in developing rat heart. American Journal of Physiology $275 \mathrm{H} 264-\mathrm{H} 273$.

Chen Y-R, Wang X, Templeton D, Davis RJ \& Tan T-H 1996 The role of c-Jun N-terminal kinase (JNK) in apoptosis induced by ultraviolet $\mathrm{C}$ and $\gamma$ radiation. Journal of Biological Chemistry 271 31929-31936.

Cross HR, Murphy E, Bolli R, Ping P \& Steenbergen C 2002 Expression of activated $\mathrm{PKC}$ epsilon (PKCE) protects the ischaemic heart, without attenuating ischaemic $\mathrm{H}^{+}$production. Journal of Molecular and Cellular Cardiology 34 361-367.

Eynan M, Knubuvetz T, Meiri U, Navon G, Gerstenblith G, Bromberg Z, Hasin Y \& Horowitz M 2002 Heat acclimationinduced elevated glycogen, glycolysis, and low thyroxine improve heart ischaemic tolerance. Journal of Applied Physiology 93 2095-2104.

Franklyn JA, Gammage MD, Raymsden DB \& Sheppard MC 1984 Thyroid status in patients after acute myocardial infarction. Clinical Science 67 585-590.

Fryer LGD, Holness MJ, Decock JB \& Sugden MC 1998 Cardiac protein kinase $\mathrm{C}$ expression in two models of cardiac hypertrophy associated with an activated cardiac renin-angiotensin system: effect of experimental hyperthyroidism and genetic hypertension (the mRen-2 rat). Journal of Endocrinology 158 27-33.

Fryer R, Wang Y, Hsu A \& Gross G 2001 Essential activation of protein kinase $\mathrm{C}-\delta$ in opioid-initiated cardioprotection. American Journal of Physiology 280 H1346-H1353.

Fryer R, Hsu A, Wang Y, Henry M, Eells J \& Gross G 2002 PKC $\delta$ inhibition does not block preconditioning induced preservation in mitochodrial ATP synthesis and infarct size reduction in rats. Basic Research in Cardiology 97 47-54.

Gabai VL, Meriin AB, Mosser DD, Caron AW, Rits S, Shifrin VI \& Sherman MY 1997 Hsp70 prevents activation of stress kinases - a novel pathway of cellular thermotolerance. Journal of Biological Chemistry 272 18033-18037.

Gabai VL, Meriin AB, Yaglom JA, Volloch VZ \& Sherman MY 1998 Role of Hsp70 in regulation of stress-kinase JNK: implications in apoptosis and aging. FEBS Letters 438 1-4.

Hak AE, Pols H, Visser TJ, Drexhage HA, Hofman A \& Witteman JCM 2000 Subclinical hypothyroidism is an independent risk factor for atherosclerosis and myocardial infarction in elderly women: The Rotterdam Study. Annals of Internal Medicine 132 270-278.

Hamilton MA, Stevenson LW, Foranow GC, Steimle A, Goldhaber JI, Childs JS, Chopra IJ, Moriguchi JD \& Hage A 1998 Safety and hemodynamic effects of intravenous triiodothyronine in advanced congestive heart failure. American Journal of Cardiology $\mathbf{8 1}$ 443-447.

Kawamura S, Yoshida K, Miura T, Mizukami Y \& Matsuzaki M 1998 Ischaemic preconditioning translocates $\mathrm{PKC}-\delta$ and $-\varepsilon$, which mediate functional protection in isolated rat hearts. American Journal of Physiology 275 H2266- 2271.

Kiss E, Jakab G, Kranias EG \& Edes I 1994 Thyroid hormoneinduced alterations in phospholamban protein expression. Regulatory effects on sarcoplasmic reticulum $\mathrm{Ca}^{2+}$ transport and myocardial relaxation. Circulation Research 75 245-251.

Klein I \& Ojamaa K 2001 Thyroid hormone - targeting the heart. Endocrinology 142 11-12.

Liu Q, Clanachan AS \& Lopaschuk GD 1998 Acute effects of triiodothyronine on glucose and fatty acid metabolism during reperfusion of ischemic rat hearts. American Journal of Physiology 275 E392-E399.

Liu X, Wang J, Takeda N, Binaglia L, Panagia V \& Dhalla NS 1999 Changes in cardiac protein kinase $\mathrm{C}$ activities and isozymes in streptozotocin-induced diabetes. American Journal of Physiology 277 E798-E804. 
Ohga Y, Sakata S, Takenaka C, Abe T, Tsuji T, Taniguchi S \& Takaki M 2002 Cardiac dysfunction in terms of left ventricular mechanical work and energetics in hypothyroid rats. American Journal of Physiology 283 H631-H641.

Pantos C, Mourouzis I, Tzeis S, Malliopoulou V, Cokkinos DD, Asimakopoulos P, Carageorgiou H, Varonos DD \& Cokkinos DV 2000 Propranolol diminishes cardiac hypertrophy but does not abolish acceleration of the ischemic contracture in hyperthyroid hearts. Journal of Cardiovascular Pharmacology 36 384-389.

Pantos C, Malliopoulou V, Mourouzis I, Karamanoli E, Tzeis SM, Carageorgiou H, Varonos D \& Cokkinos DV 2001 Long-term thyroxine administration increases HSP70 mRNA expression and attenuates p38 MAP kinase activity in response to ischaemia. Journal of Endocrinology 170 207-215.

Pantos C, Malliopoulou V, Mourouzis I, Karamanoli E, Paizis I, Steimberg N, Varonos D \& Cokkinos DV 2002a Long-term thyroxine administration protects the heart in a similar pattern as ischaemic preconditioning. Thyroid 12 325-329.

Pantos C, Mourouzis I, Delbruyere M, Malliopoulou V, Tzeis S, Cokkinos DD, Nikitas N, Carageorgiou H, Varonos D, Cokkinos DV et al. $2002 b$ Effects of dronedarone and amiodarone on plasma thyroid hormones and on the basal and postischemic performance of the isolated rat heart. European Journal of Pharmacology 444 191-196.

Pantos C, Malliopoulou V, Paizis I, Moraitis P, Mourouzis I, Tzeis S, Karamanoli E, Cokkinos DD, Carageorgiou H, Varonos D et al. 2003a Thyroid hormone and cardioprotection; study of p38 MAPK and JNKs during ischaemia and at reperfusion in isolated rat heart. Molecular and Cellular Biochemistry 242 173-180.

Pantos C, Malliopoulou V, Mourouzis I, Moraitis P, Tzeis S, Thempeyioti A, Paizis I, Cokkinos AD, Carageorgiou H, Varonos D et al. 20036 Involvement of p38 MAPK and JNK in the heat stress-induced cardioprotection. Basic Research in Cardiology $\mathbf{9 8}$ 158-164.

Pantos C, Mourouzis I, Tzeis S, Moraitis P, Malliopoulou V, Cokkinos DD, Carageorgiou H, Varonos D \& Cokkinos DV 2003 c Dobutamine administration exacerbates postischaemic myocardial dysfunction in isolated rat hearts: an effect reversed by thyroxine pre-treatment. European Journal of Pharmacology 460 155-161.
Sato M, Cordis GA, Maulik N \& Das DK 2000 SAPKs regulation of ischaemic preconditioning. American Journal of Physiology 279 H901-H907.

Shenoy R, Klein I \& Ojamaa K 2001 Differential regulation of SR calcium transporters by thyroid hormone in rat atria and ventricles. American Journal of Physiology 281 H1690-H1696.

Speechly-Dick M, Mocanou M \& Yellon D 1994 Protein kinase C: its role in ischaemic preconditioning in the rat. Circulation Research 75 586-590.

Vanderpump MP \& Tunbridge WM 2002 Epidemiology and prevention of clinical and subclinical hypothyroidism. Thyroid 12 839-847.

Van Der Vusse GJ, Coumans WA, Ulrich M \& Van Bilsen M 1998 Thyroxine induced alteration in cardiac energy metabolism. Journal of Molecular and Cellular Cardiology 30 A110.

Verheij M, Bose R, Lin XH, Yao B, Jarvis WD, Grant S, Birrer MJ, Szabo E, Zon LI, Kyriakis JM et al. 1996 Requirement for ceramideinitiated SAPK/JNK signalling in stress-induced apoptosis. Nature $38075-79$

Walker JD, Crawford FA Jr \& Spinale FG 1995 3,5,3' Triiodo-Lthyronine pretreatment with cardioplegic arrest and chronic left ventricular dysfunction. Annals of Thoracic Surgery 60 292-299.

Walker JM 1994 Basic Protein and Peptide Protocols. Totowa, NJ: Humana Press.

Yue TL, Ma XL, Gu JL, Ruffolo RR Jr \& Feuerstein GZ 1998 Carvedilol inhibits activation of stress-activated protein kinase and reduces reperfusion injury in perfused rabbit heart. European Journal of Pharmacology 345 61-65.

Zhang L, Parratt JR, Beastall GH, Pyne NJ \& Furman BL 2002 Streptozotocin diabetes protects against arrhythmias in rat isolated hearts: role of hypothyroidism. European Journal of Pharmacology 435 269-276.

Zhao J, Renner O, Wightman L, Sugden P, Stewart L, Latchman D \& Marber MS 1998 The expression of constitutively active isotypes of protein kinase $\mathrm{C}$ to investigate preconditioning. Journal of Biological Chemistry 273 23072-23079.

Received 2 March 2003

Accepted 10 June 2003 